سلوكية عتبات التربة الجبسية المثبتة بالنورة تحت تأثير الأحمال الساكنة
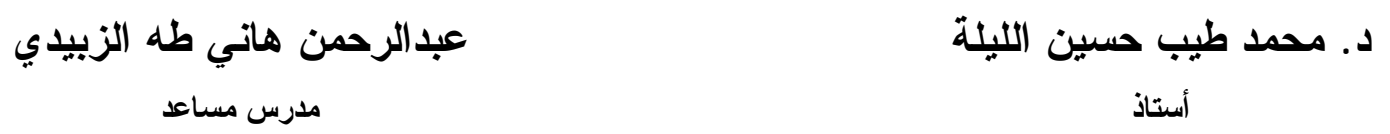

كلية الهندسة - جامعة الموصل

الخلاصة

يهدف هذا البحث إلى دراسة منحنيات الإجهاد -الانفعال, لتربة جبسية تعرضت إلى اجهادات شد. حيث تـم

معاملة التربة بنسبة (3\%) نورة وهي النسبة المفضلة ثم حضرت نماذج بأبعاد

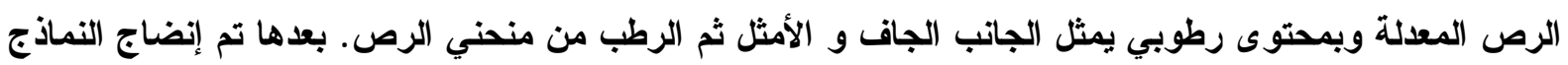

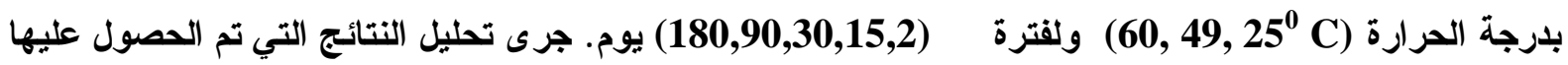

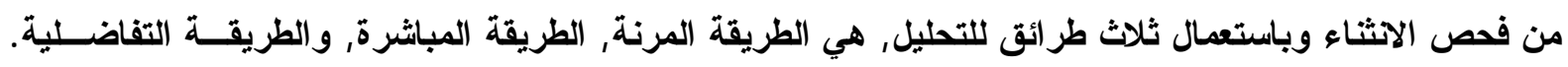
كانت نتائج مقاومة الثد وحسب الطريقة المرنة والطريقة المباثرة وبصورة عامة متقاربة. في حين كانت مقاومة

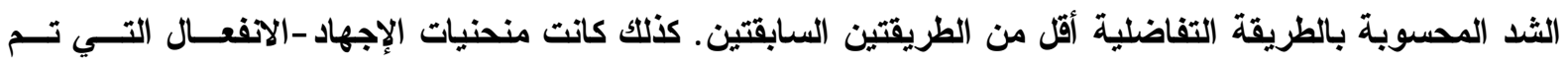
الحصول عليها من الطريقة المرنة منتظمة, في حين كانت المنحنيات غير منتظمة عند حسابها بالطريقة المباثــرة و الطريقة التفاضلية, ماعدا منحنيات النماذج التي تم رصها عند المحتوى الرطوبي الذي يمثل الجاتب الجــاف مسن فئن

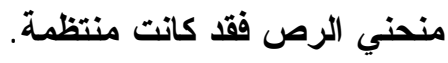

\title{
Behavior of Lime Stabilized Gypseous Soil Beams Under static Loads
}

\author{
M. T. Al- Layla \\ Professor \\ A. H. Al - Zubaydi \\ Ass. Lecture
}

University of Mosul - College of Engineering

\begin{abstract}
This work aims to study the stress-strain curves of soil samples subjected to tensile stress. The samples $(50 * 50 * 300 \mathrm{~mm})$ were prepared from lime stabilized gypseous soil using (3\%) lime as stabilization percent. The samples were cured at $(25,49$ and $\left.60^{\circ} \mathrm{C}\right)$ for a period of $(2,15,30,90$ and 180$)$ days. The results obtained from flexural tensile tests were analyzed using three methods of analysis. These methods are, the elastic bending theory, direct, and differential method. The elastic and the direct methods gave, generally similar results of the soil flexural tensile stress while the differential method gave lower values. Also the tensile stress-strain curves obtained by the elastic method were consistent, while the curves from direct and differential methods are in consistent, with the exception of the samples compacted at the dry side of the compaction curve.
\end{abstract}




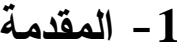

تتميز التربة في حالتها الطبيعية بضعف مقاومتها الثدية مقارنةً مع المقاومة الانضعاطية[1]. إذ إن اجهادات

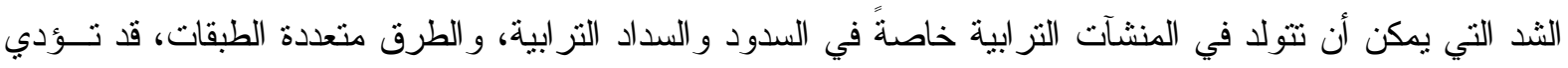
إلى فنثل هذه المنشآت إذا كانت قيم هذه الاجهادات أعلى من مقاومة الثد للتربة.

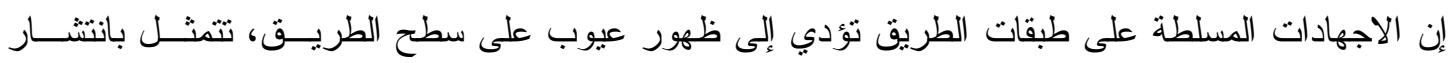

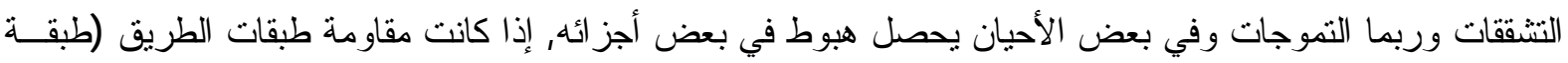

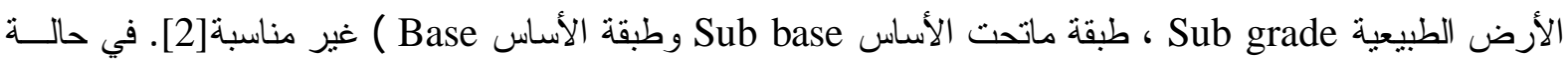

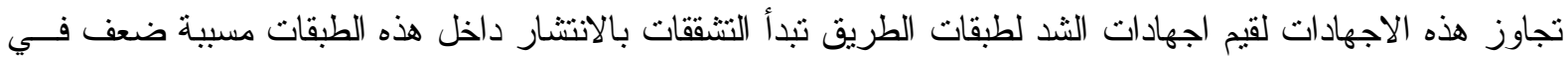

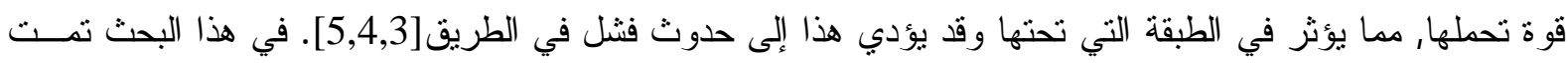
در اسة سلوكية منحنيات الإجهاد -الانفعال لتربة جبسية ذات محتوى جبسي (35\%) من منطقة المحلبية قرب مدينة الموصل, منثتة بنسبة (3\%) نورة ونم إجر اء فحص الانثتاء (Flexural Tensile Test) وتحليل النتــائج باســتخدام الطريقة المرنة (Elastic Bending Theory Method) و الطريقــة المباشــرة (Direct Method) و الطريقـــة التفاضلية (Differential Method).

\section{2 - المو اد وطر ائق العمل}

1- 2

اختيرت التزبة المستخدمة في هذه الدراسة من منطقة المحلبية التي تقع في الجزء الجنوبي الغربي من مدينة

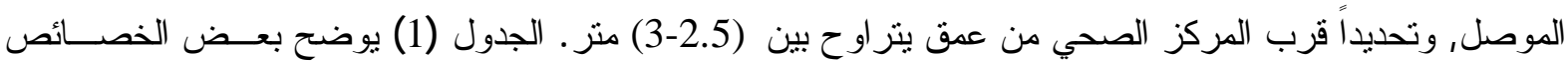
الدليلية و الكيميائية لهذه التزبة و التي أجريت حسب مو اصفات (ASTM).

2-2

تم في هذا البحث استعمال النورة المطفأة Hydrated Lime Ca(OH) مجمع المشر اف في محافظة نينوى ويبين الجدول (2) التركيب الكيمياوي للنورة المستعملة، إذ كانت من نوع (Brade)

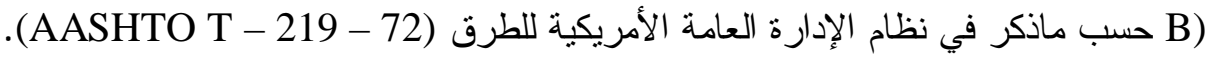

2-3

في هذا البحث تم استعمال ماء الإسالة في جميع التجارب إلا ما نصت عليه المو اصــفات باســـخدام المــاء

المقطر Distilled water

\section{- تحضير و إنضاج النماذج المثبتة بالنورة.}

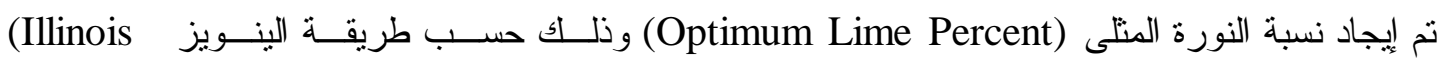
Procedure)

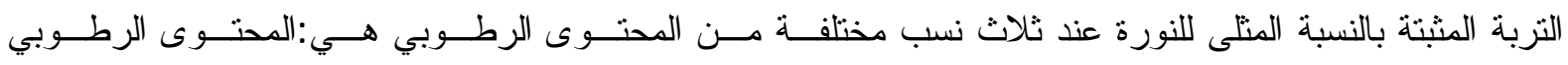

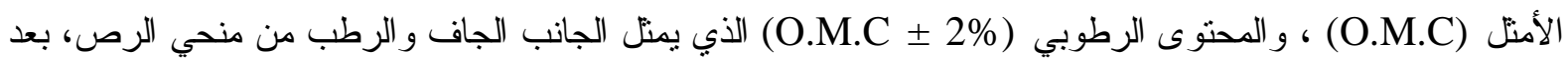

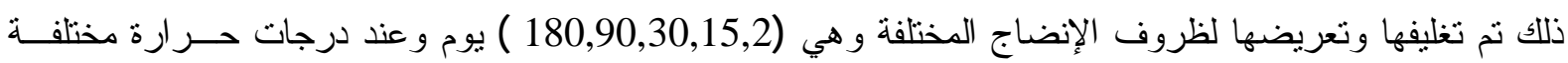
(60,49,25) 


\section{الجدول (1) خواص التربة الطبيعية}

\begin{tabular}{|c|c|c|}
\hline القيمة (Value) & \multicolumn{2}{|l|}{ الخاصية (Property) } \\
\hline 35 & \multicolumn{2}{|r|}{ نسبة الجبس (\%) } \\
\hline 1.32 & $(\%)\left(\mathrm{SO}_{3}\right)$ & نسبة أملاح الكبريتات \\
\hline 0.284 & \multicolumn{2}{|c|}{ محتوى المو اد العضوية (\%) } \\
\hline 2.41 & \multicolumn{2}{|r|}{ الوزن النوعي (Gs) } \\
\hline $\mathrm{NP}$ & حد السيولة (L.L) (\%) & \multirow{3}{*}{ حدود أنزبرك } \\
\hline NP & حد اللدونة (P.L) (\%) & \\
\hline---- & دليل اللدونة (P.I) (\%) & \\
\hline 7.28 & \multicolumn{2}{|c|}{ الرقم الهيدروجيني (pH) } \\
\hline 74 & نسبة الرمل (\%) & \multirow{3}{*}{$\begin{array}{r}\text { التنرج الحبيبي للتربة } \\
\text { EDTA } \\
\text { المغسولة بواسطة }\end{array}$} \\
\hline 11 & نسبة الغرين (\%) & \\
\hline 15 & نسبة الطين (\%) & \\
\hline 74 & 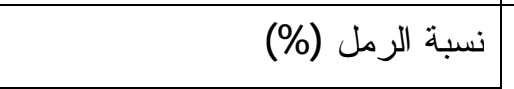 & \multirow{3}{*}{ 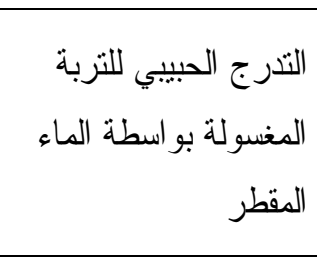 } \\
\hline 16 & نسبة الغرين (\%) & \\
\hline 10 & نسبة الطين (\%) & \\
\hline SC-SM & نظام التصنيف الموحد & \multirow{2}{*}{ تصنيف التربة } \\
\hline A -3 (0) & نظام الإدارة العامة الأمريكية للطرق & \\
\hline
\end{tabular}

الجدول (2) التركيب الكيمياوي للنورة

\begin{tabular}{|c|c|c|c|c|c|c|c|c|}
\hline $\mathrm{H}_{2} \mathrm{O}$ & MgO & $\mathrm{SiO}_{2}$ & $\mathrm{Fe}_{2} \mathrm{O}_{3}$ & $\mathrm{Al}_{2} \mathrm{O}_{3}$ & $\mathrm{CaCO}_{3}$ & $\mathrm{CaO}$ & $\mathrm{Ca}(\mathrm{OH})_{2}$ & المكونات \\
\hline 0.08 & 3.89 & 11.36 & 0.05 & 0.16 & 5.53 & 6.43 & 72.5 & النسبة (\%) \\
\hline
\end{tabular}

3 -فحص الاتثناء

1-3

أستخدم قالب معدني مستطيل الثكل بأبعاد (300*50*50 mm) ذي جو انب منزلقة لتحضير النماذج، إذ تم

رص التربة فيه لتعطي طاقة الرص المعلة (Modified Compacted Effort) . بعد إكمال عملية الرص يستخرج

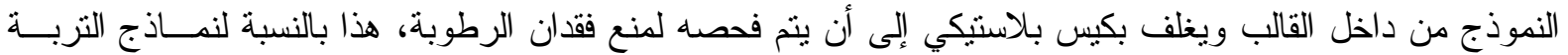

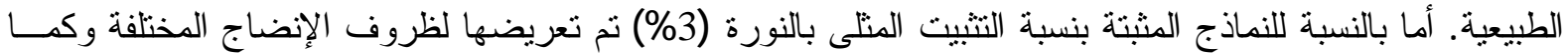


3 -2 إجراء فحص الانثاء.

تم فحص النماذج التي هي على شكل عتبة (Beam) حسب الطريقة المذكورة فــي المو اصــفات البريطانيــة

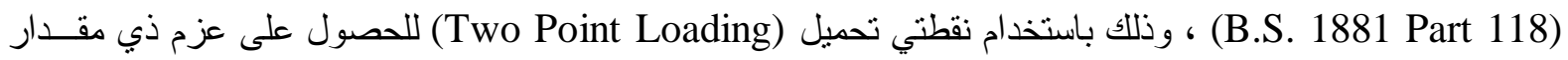

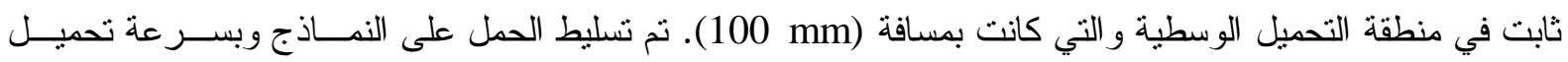

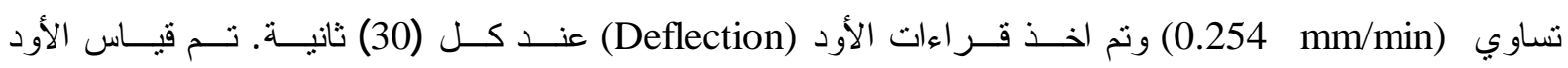
الحاصل في النموذج خلال فحص الانثاء، إذ لصقت قطعة زجاجية مستطيلة الثكل ذات سمك مناسب الأبه (Deflection) في المنطقة الوسطى السفلية للنموذج (أسفل مركز النموذج) ونم استخدام Dial Gauge بحساســية تشــاوي

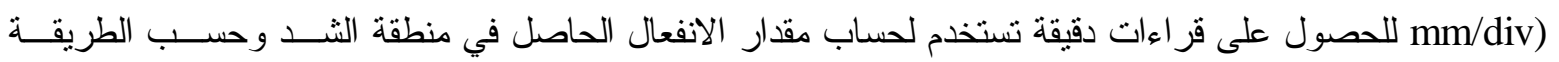

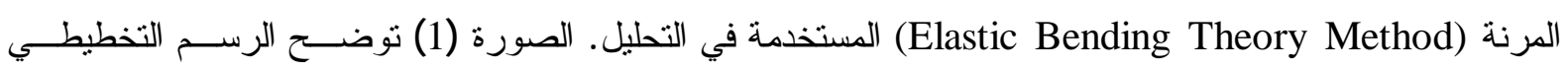
لطريقة فحص الانثناء.

Loading Plate with Two Rods

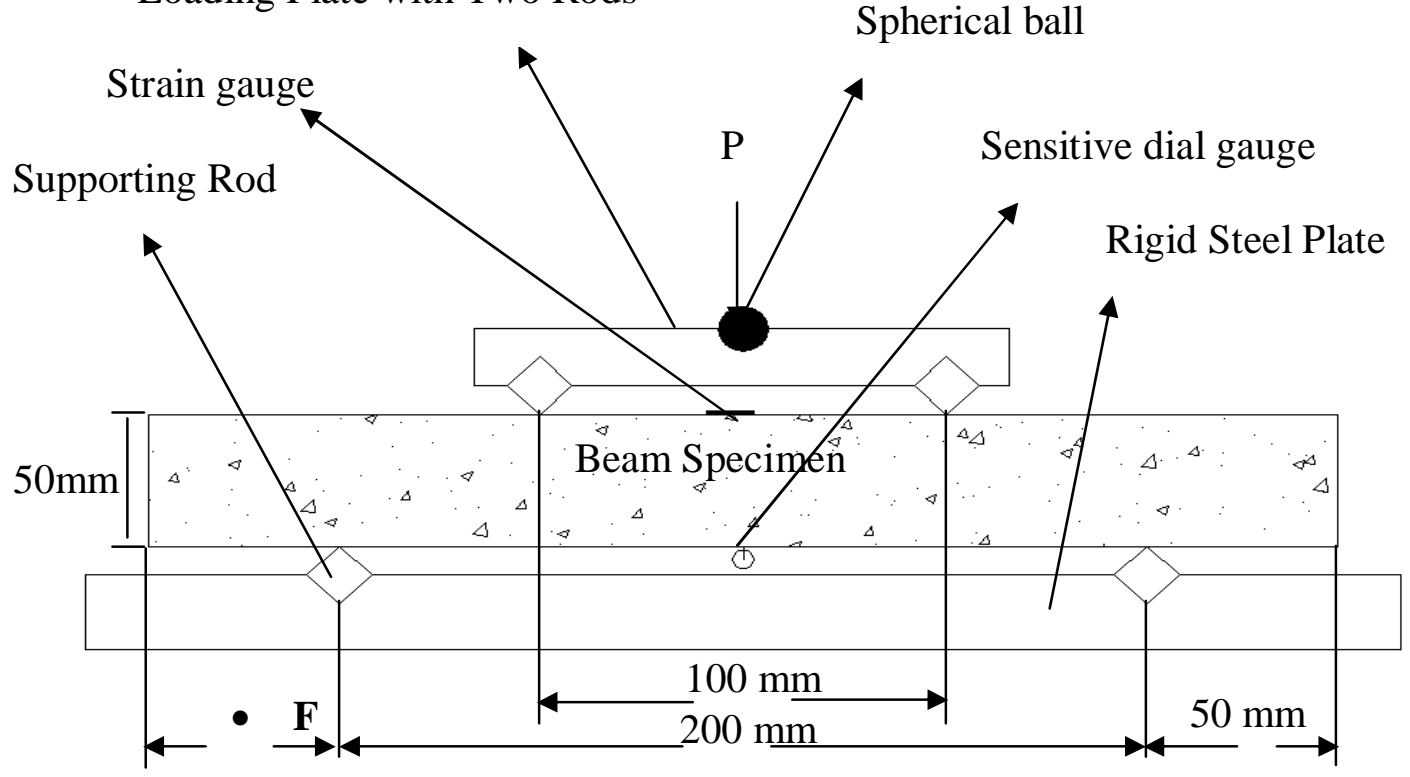

الصورة (1) رسم تخطيطي يوضح طريقة فحص الانثناء(Flexural Test)

\section{4 - طرائق تحليل الإجهاد في العتبة.} إن تحليل الإجهاد الحاصل في العتبة خلال فحص الانثتاء يمكن أن يتم باستخدام ثلاث طر ائق للتحليل[7] هذه

$$
\text { الطر ائق هي: - }
$$

1.الطريقة المباشرة Direct Method .

2. Differential Method الطريقة التفاضلية

3. Elastic Bending Theory Method الطريقة المرنة الطربهة

استخدمت الطر ائق أعلاه لحساب إجهاد الثد (Tensile Stress) الذي يحصل في أسفل العنبة وإجهاد الانضغاط (Compressive Stress) الذي يحصل في أعلى العتبة خلال تسليط عزم الانحناء. بالنسبة لكل من الطريقة الأولى و الثانية من طر ائق التحليل, تم حساب الإجهاد من خلال العزم المسلط على العتبة ومن خلال الانفعال (Strain) 
المقاس في منطقة الثد ومنطقة الانضغاط، و الذي ثم باستخدام مقاييس الانفعال (Electrical Strain Gauges) وجهاز قياس الانفعال (Strain Meter) وكان الربط بين هذه المقاييس من نوع (Half Bridge) .أما بالنسبة للطريقة

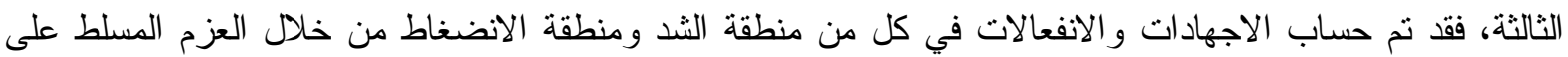
العتبة ومن خلال الأود (Deflection) المقاس عند منتصف العتبة.

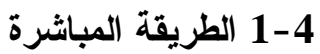
في هذه الطريقة نم افتر اض بقاء المقاطع المستوية (Plane sections) على حالتها حتى بعد تسليط العزم (أي لايحصل بها انحناء) ، هذا يعني إن الإجهاد يتغير خطيا تبعاً للانفعال، ولكن معامل النشوه Deformation) في منطقة الثد يمكن أن يختلف عنه في منطقة الضغط وذلك لان المحور المتعادل ( Neutral axis) ليس بالضرورة أن يكون في منتصف ارتفاع العتبة، كذلك نم افتراض عدم حصول زحف (Creep) خلال عملية الانحناء) (Bending)

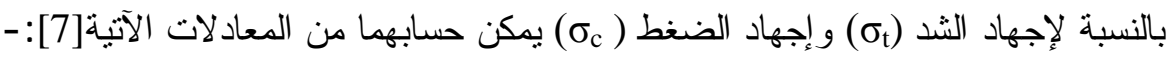

$\begin{aligned} \sigma_{t} & =\frac{3 M\left(\varepsilon_{c}+\varepsilon_{t}\right)}{b h^{2} \varepsilon_{t}} \\ \sigma c & =\frac{3 M\left(\varepsilon_{c}+\varepsilon_{t}\right)}{b h^{2} \varepsilon_{c}}\end{aligned}$

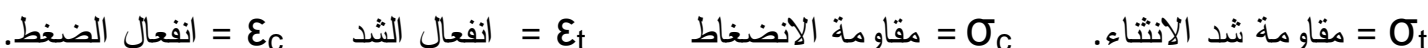

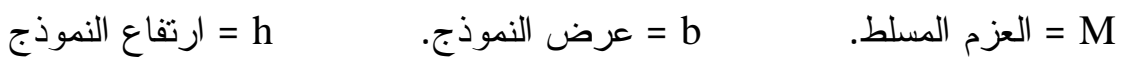

4

لحساب مقدار الاجهادات الحاصلة في العتبة باستخدام الطريقة التفاضلية، نم افتزاض بقاء المقاطع المستوية (Plane sections) على حالتها حتى بعد نسليط العزم، كذلك نم افتر اض عدم حصول أب زحف (Creep) خلا تسليط العزم وحصول انحناء للعنبة. بالنسبة للعلاقة بين الإجهاد و الانفعال لم تكن هنالك علاقة خطية بينهما، وان الإجهاد الحاصل في العتبة بسبب العزم المسلط هو دالة للانفعال الخطي (ع) و الذي لبس بالضرورة أن يكون نفسه في منطقة الثد ومنطقة الضغط، هذا يعني أن العلاقة بين الإجهاد و الانفعال يمكن تمثيلها بالمعادلة آلاتية: $\sigma=f(\varepsilon)$

$\sigma_{c}=\frac{1}{\varepsilon_{c}+\varepsilon_{t}} \frac{\partial}{\partial \varepsilon_{c}}(X)$

$\sigma_{t}=\frac{1}{\varepsilon_{c}+\varepsilon_{t}} \frac{\partial}{\partial \varepsilon_{t}}(X)$ 


$$
X=\frac{M\left(\varepsilon_{c}+\varepsilon_{t}\right)^{2}}{b d^{2}}
$$

نلاحظ من خلال المعادلات أعلاه أن الحاجة إلى الاشتقاق ينم لمرة واحدة، لكي يتم حساب كل من إجهاد

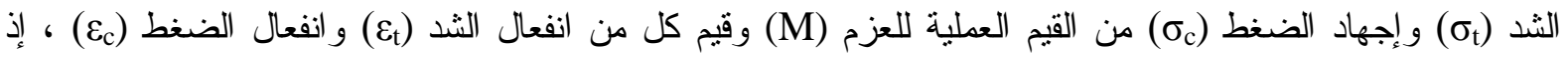
يمكن ذلك باستعمال الوسائل البيانية (Graphical Means) .إن تغاير قيم (X) مع قيم انفعال الثند (ع) و وانفعال الضغط (Ec) في هذه المعادلات يعطي قيماً عالية جدا بحيث لايمكن رسمها على مقياس رسم طبيعي ثم اثتقاقها، لذلك

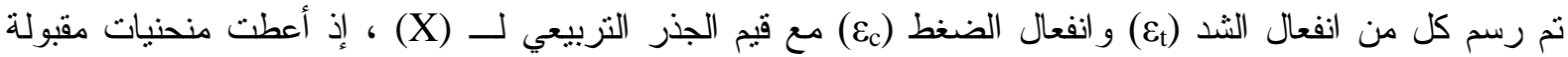
وكما مبين في الثكل (1) ونم كن إن الاشتقاق البياني نم برسم مماس عند النقاط المعنية، ونم حساب قيم كل من

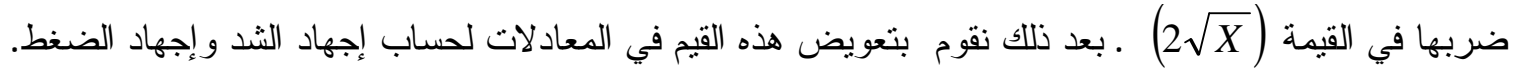

\section{4 -3 الطريقة المرنة}

هذه الطريقة مبنية على فرضيات عدة منها:المقاطع المستوية في العتبة تبقى مستوية حتى بعد حصول الانحناء، وان

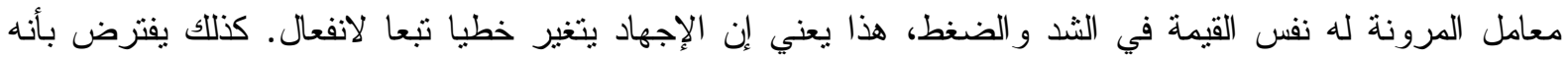
لايحدث أي انفعال ما لم تزداد قيم الإجهاد المسلط على العتبة، بصورة أخرى لايحدث أي زحف (Creep) خلال

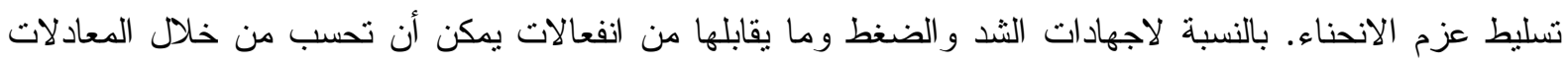
الآثين[7][: -

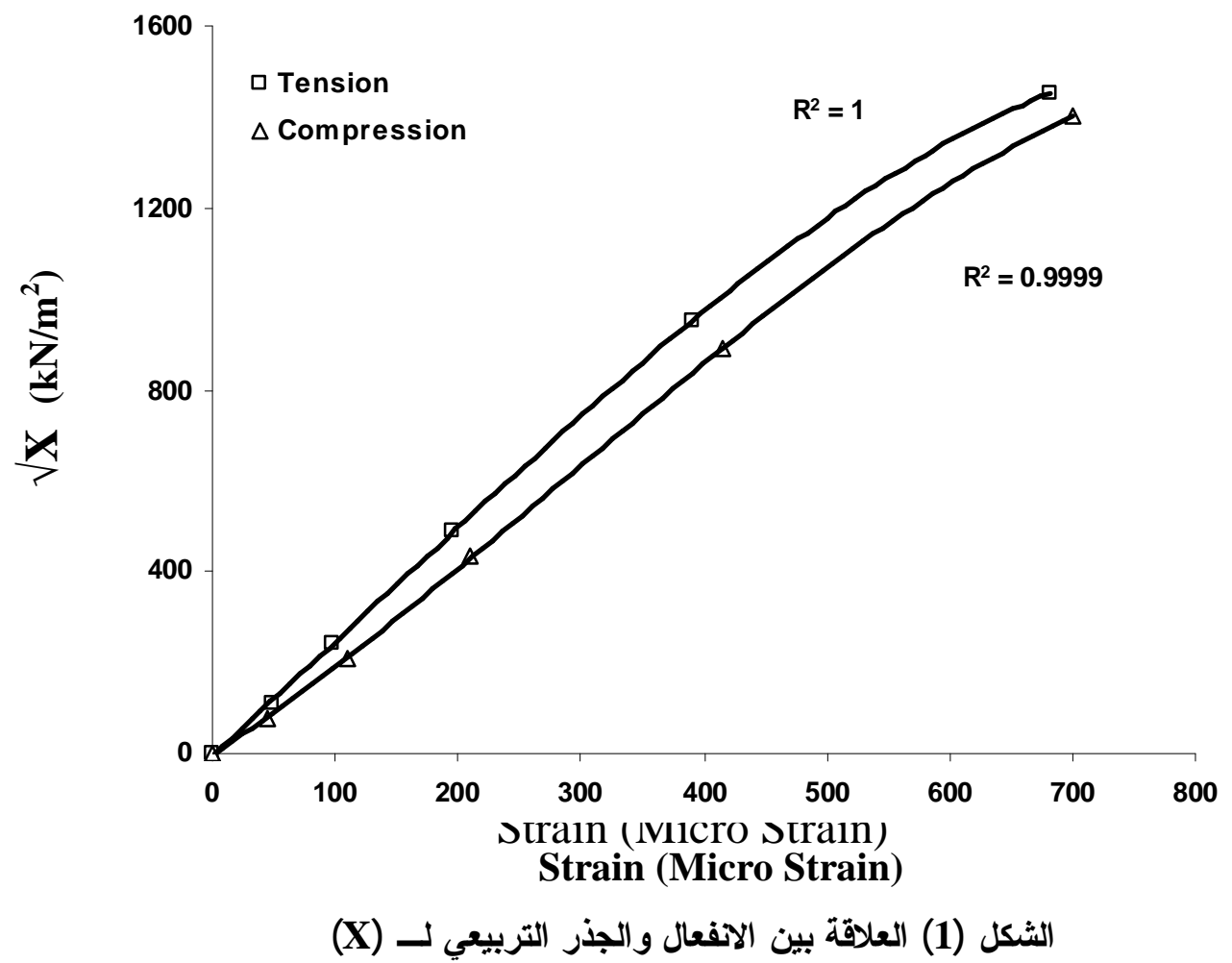




$$
\begin{aligned}
& \sigma_{t, c}=\frac{6 M}{b d^{2}} \\
& \varepsilon_{t, c}=\frac{48 * \delta * M C}{P b\left(3 L^{2}-4 b^{2}\right)}
\end{aligned}
$$

ס= مقدار الأود (Deflection) المقاس أسفل المنطقة الوسطى للعتبة.

=M العزم المسلط على العنبة. P = الحمل المسلط على العتبة. المسافة بين نقطتي الإسناد.

\section{5 - 5 - النتائج ومناقشتها \\ 1-5 مقاومة الثد ومنحنيات الإجهاد -الاخفعال}

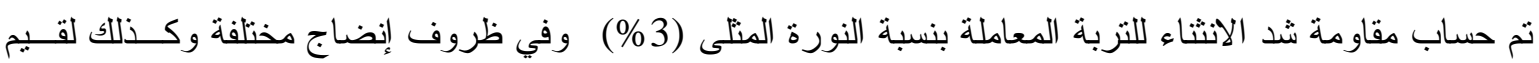
محتوى رطوبي مختلف, باستخدام ثلاث طر ائق هي: الطريقة المباثــرة (Direct Method), الطريقــة التقاضـلية (Elastic Bending Theory Method) . أعطت كل طريقة من هـــــ (Differential Method) الطر ائق قيم مختلفة لمقاومة شد الانثاء, وذلك لان كل طريقة لها فرضياتها في هذه الحسابات.

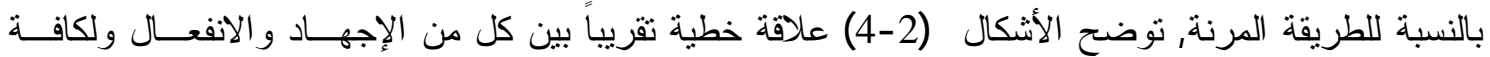
ظروف الإنضاج, تبين الأثكال أن العلاقة تقترب من كونها خطية كلما زادت درجة حرارة أو فترة الإنضاج. الأشكال

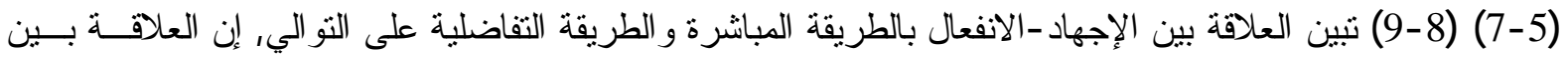
الإجهاد و الانفعال ولكلا الطريقتين تميزت بكونها علاقة غير منتظمة, هذا بسبب قيم إجهاد الثد المحسوب و الذي يعتمد

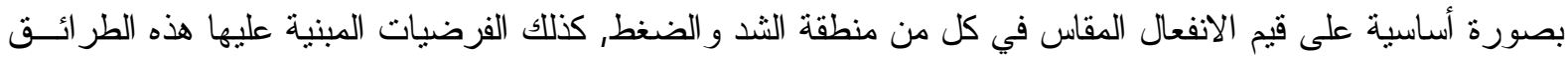

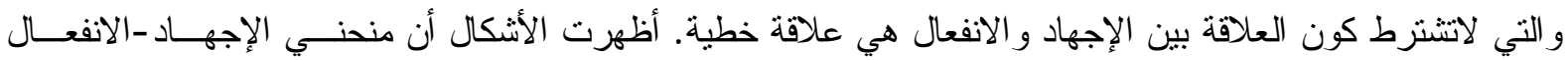
للنماذج المرصوصة عند المحتوى الرطوبي الذي يمثل الجانب الجاف من منحني الرص و المحسوب بالطريقتين كـان

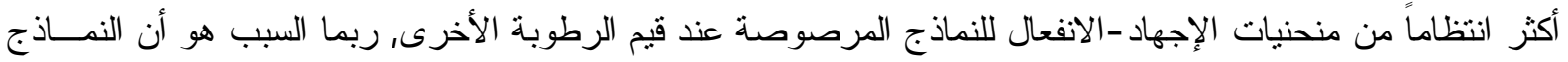

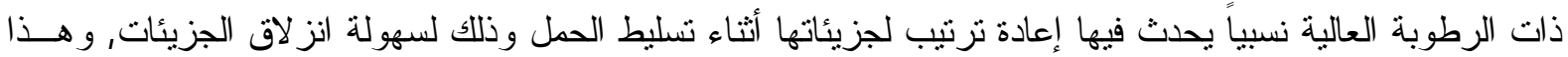
بدوره يعطي شكل منحني الإجهاد -الانفعال شكل غير منتظم.

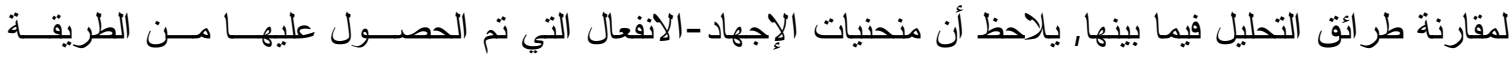
المباثرة و الطريقة التقاضلية, كانت منحنيات غير منتظمة (Irregular Shapes of Stress-Strain Curves) و هذه

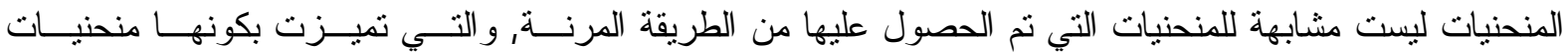

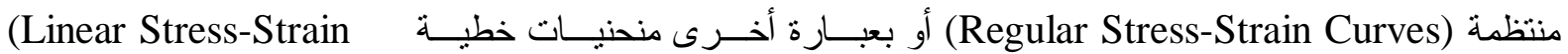
Curves)

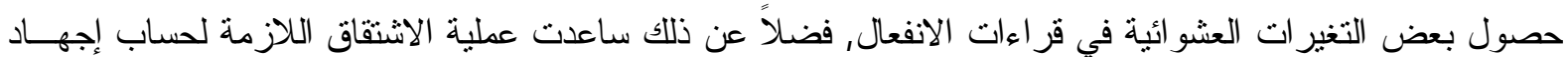

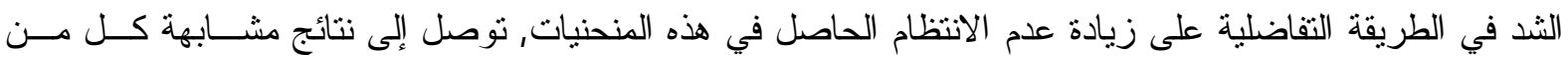
[9,8]. كذلك بينت النتائج السابقة وبصــورة عامــة أن الطريقــة المرنــــ (Elastic Bending Theory Method) و الطريقة المباثرة (Direct Method), أعطت قيم متقاربة فيما بينها لمقاومة شد الانثناء وبغض النظر عن ظــروف الإنضاج وقيم الرطوبة المختلفة, في حين أعطت الطريقة التفاضلية (Differential Method) قيم أقل لمقاومة الثد,

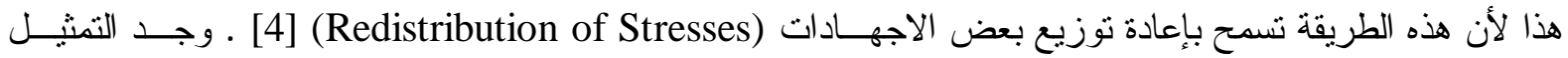


الرياضي لقيم الإجهاد المحسوب بالطر ائق الثنلاث أعلاه, وللنماذج المرصوصة عند الجانب الجاف من منحني الــرص الذي يعطي علاقة منتظمة بين الإجهاد -الانفعال مقارنةً مع قيم الرطوبة الأخرى, و عند ظروف الإنداد الإنضاج المختلفة. يبين

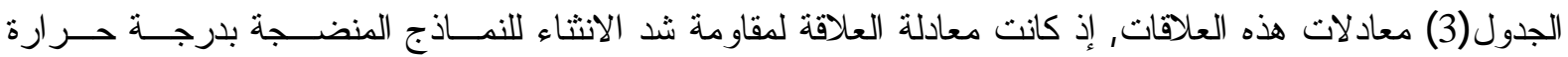

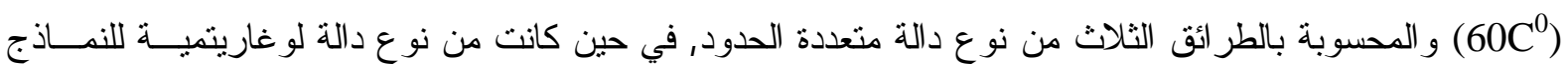

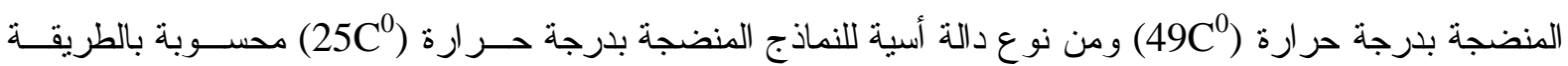

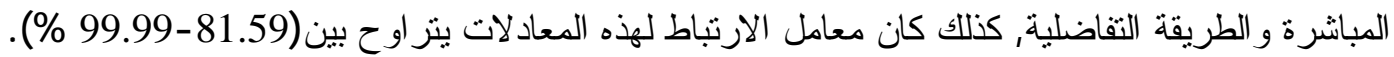
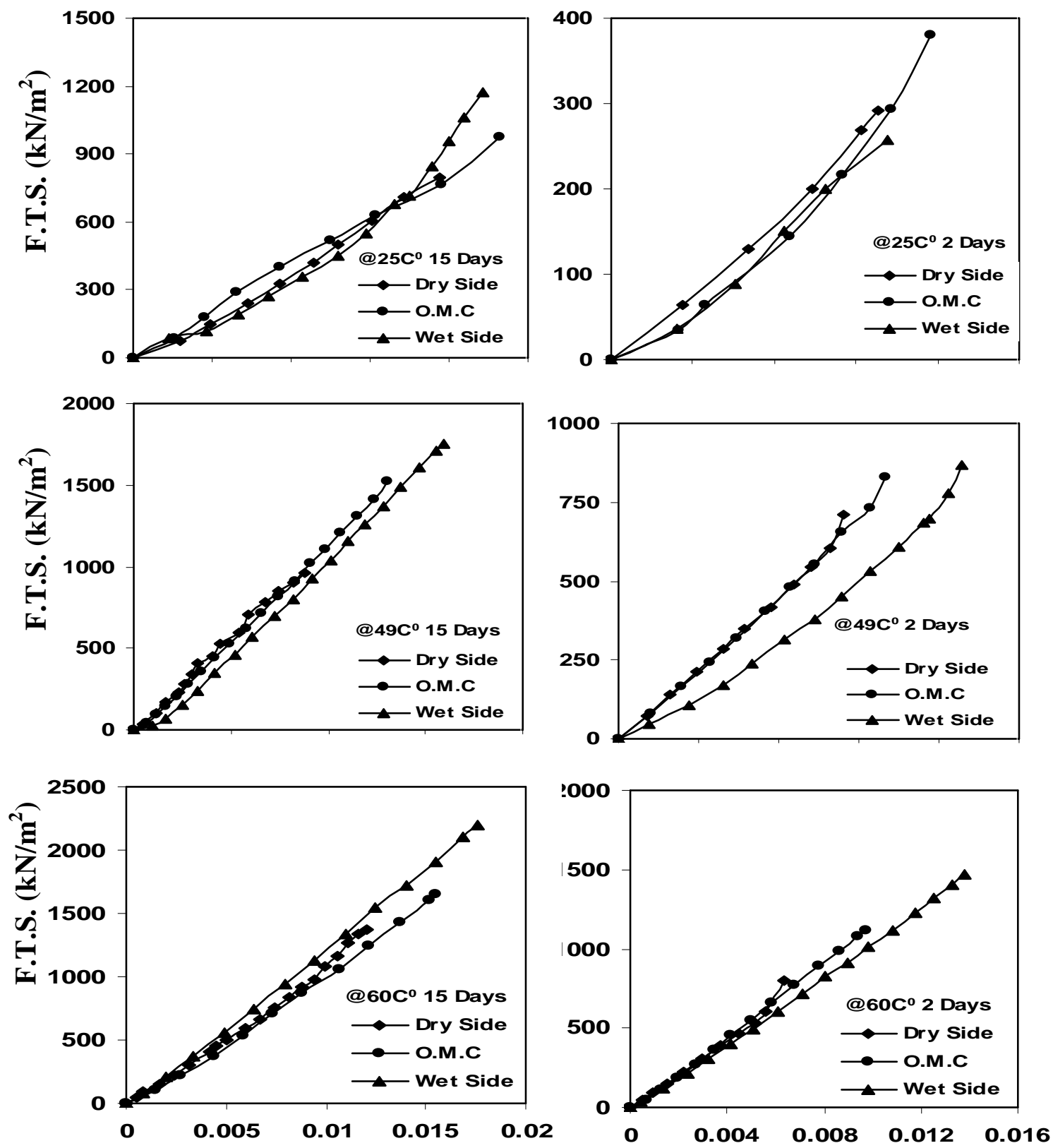

- $\quad$ F.T.S = Flexural Tensile Stress

Tensile Strain

Tensile Strain

الثكل (2) منحنيات الإجهاد -الانفعال (حسب الطريقة المرنة) 
ألليلة: سلوكية عتبات التربة الجبسية المثبتة بالنورة تحت تأثير الأحمال الساكنة
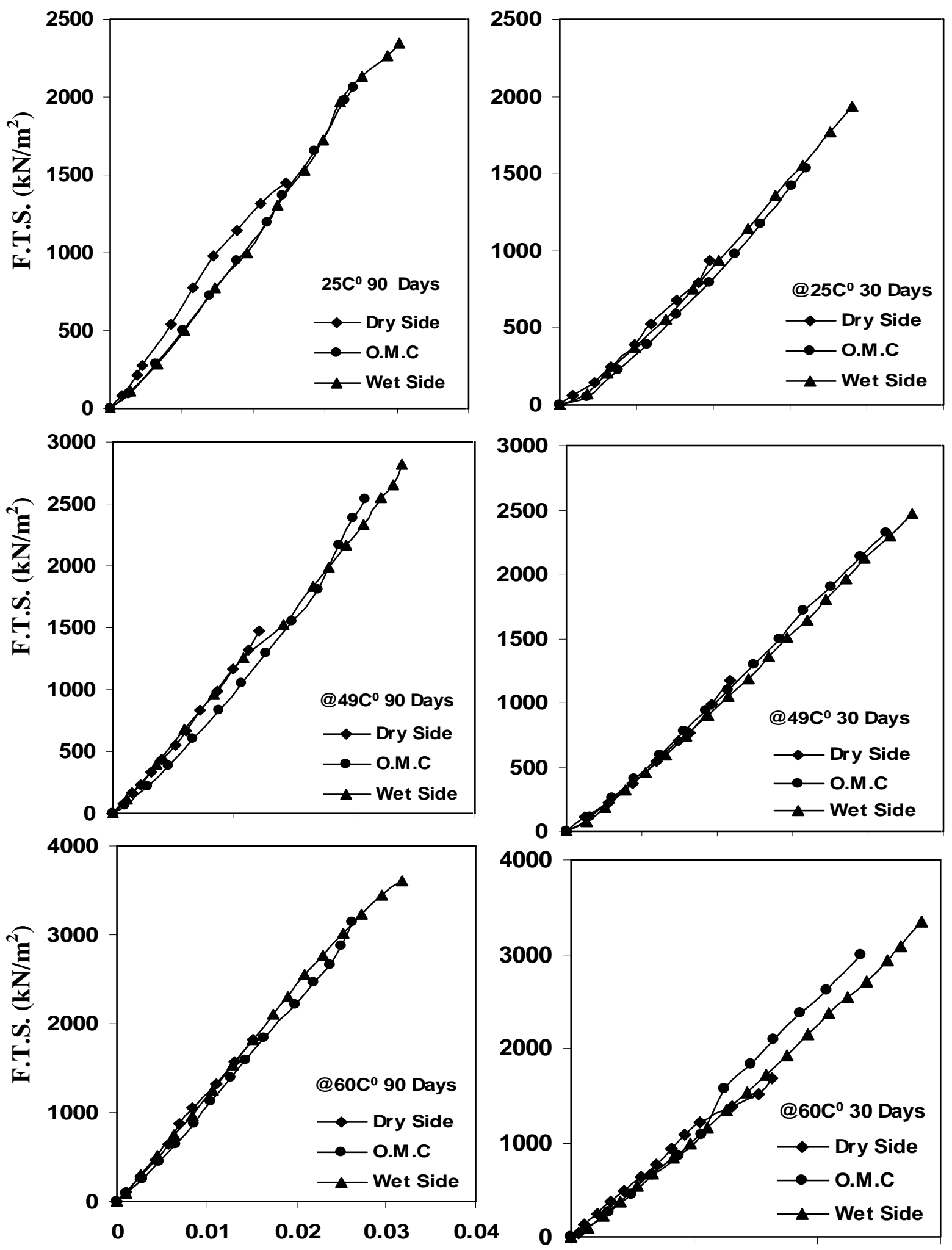

Tensile Strain

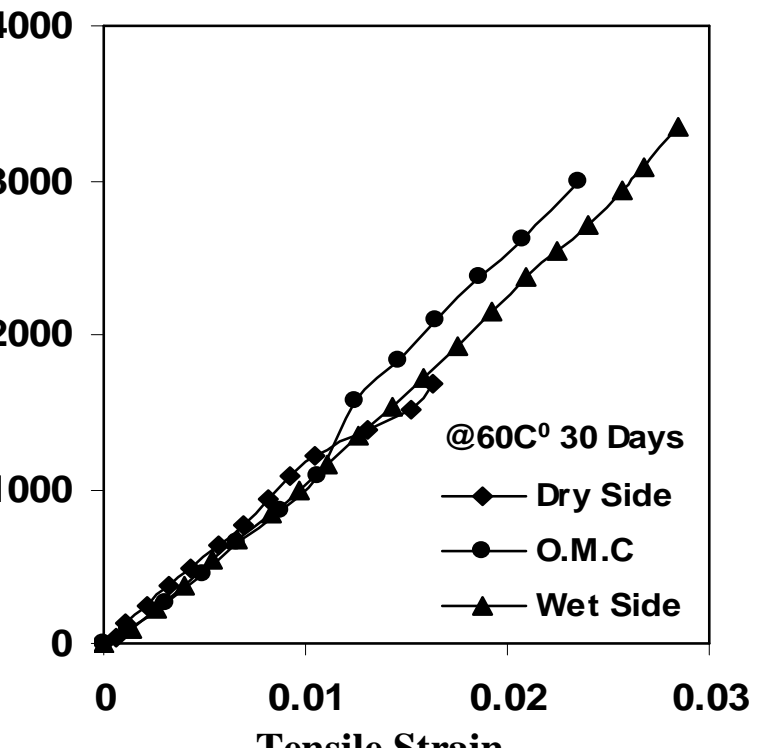

Tensile Strain

الثكل (3) منحنيات الإجهاد -الانفعال (حسب الطريقة المرنة) 

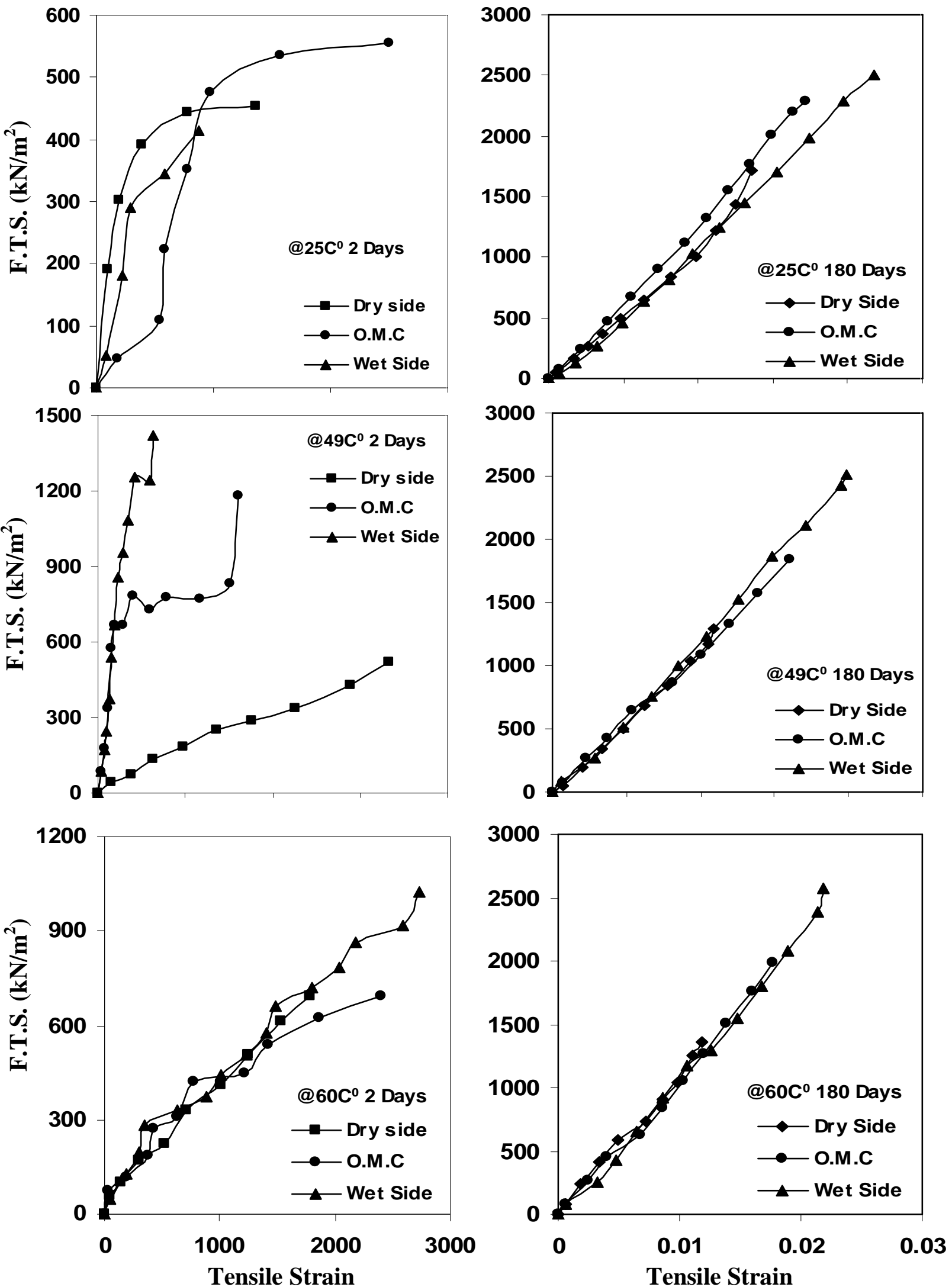

$$
\begin{aligned}
& \text { الثكل (5) منحنيات الإجهاد -الاففعال } \\
& \text { (حب الطريقة المباشرة) }
\end{aligned}
$$

$$
\begin{gathered}
\text { الثكل (4) منحنيات الإجهاد -الانفعال } \\
\text { (حسريقة المرنة) }
\end{gathered}
$$


ألليلة: سلوكية عتبات التربة الجبسية المثبتة بالنورة تحت تأثير الأحمال الساكنة
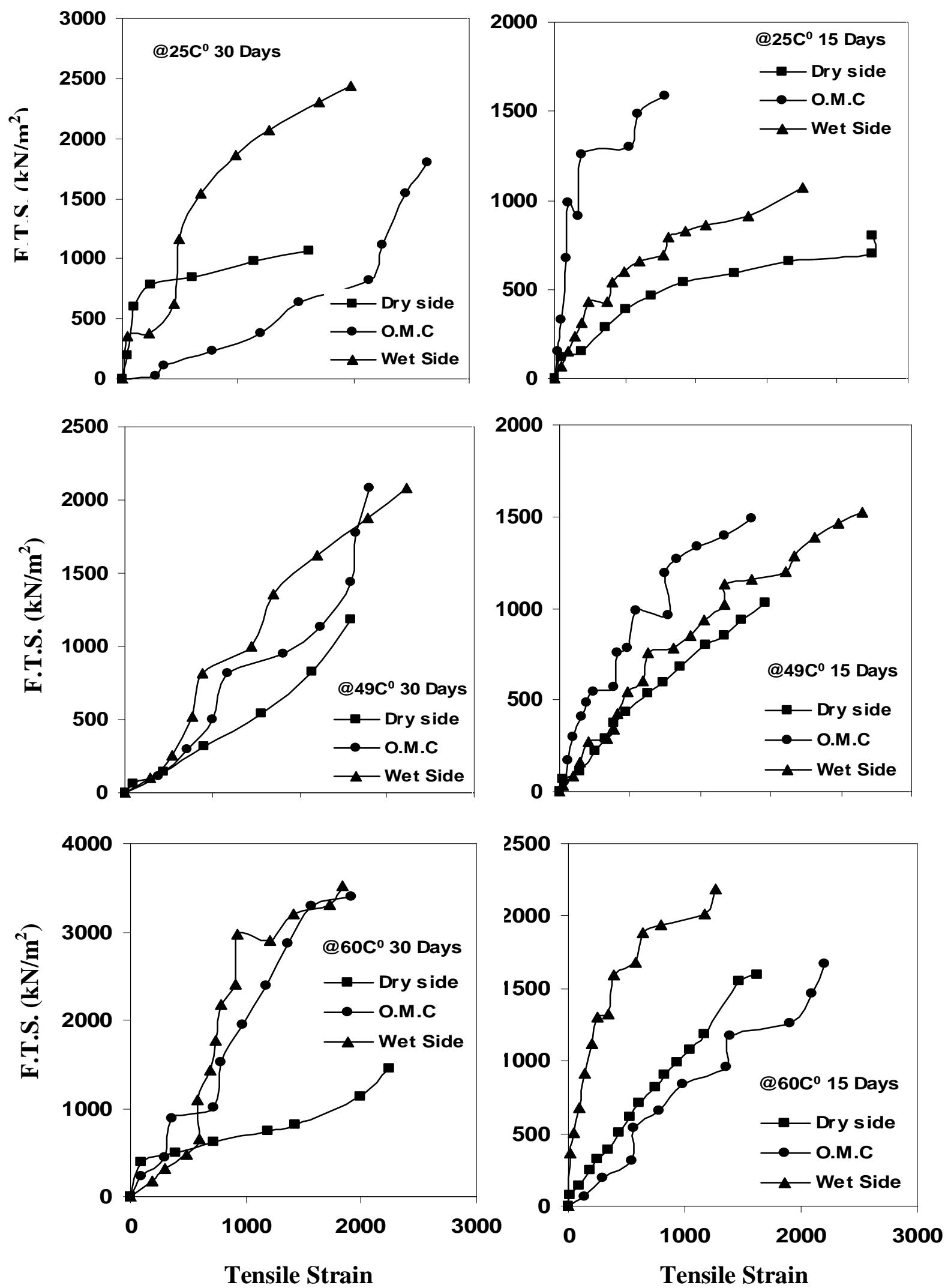

الثكل (6) منحنيات الإجهاد -الانفعال (حب الطريقة المباشرة) 

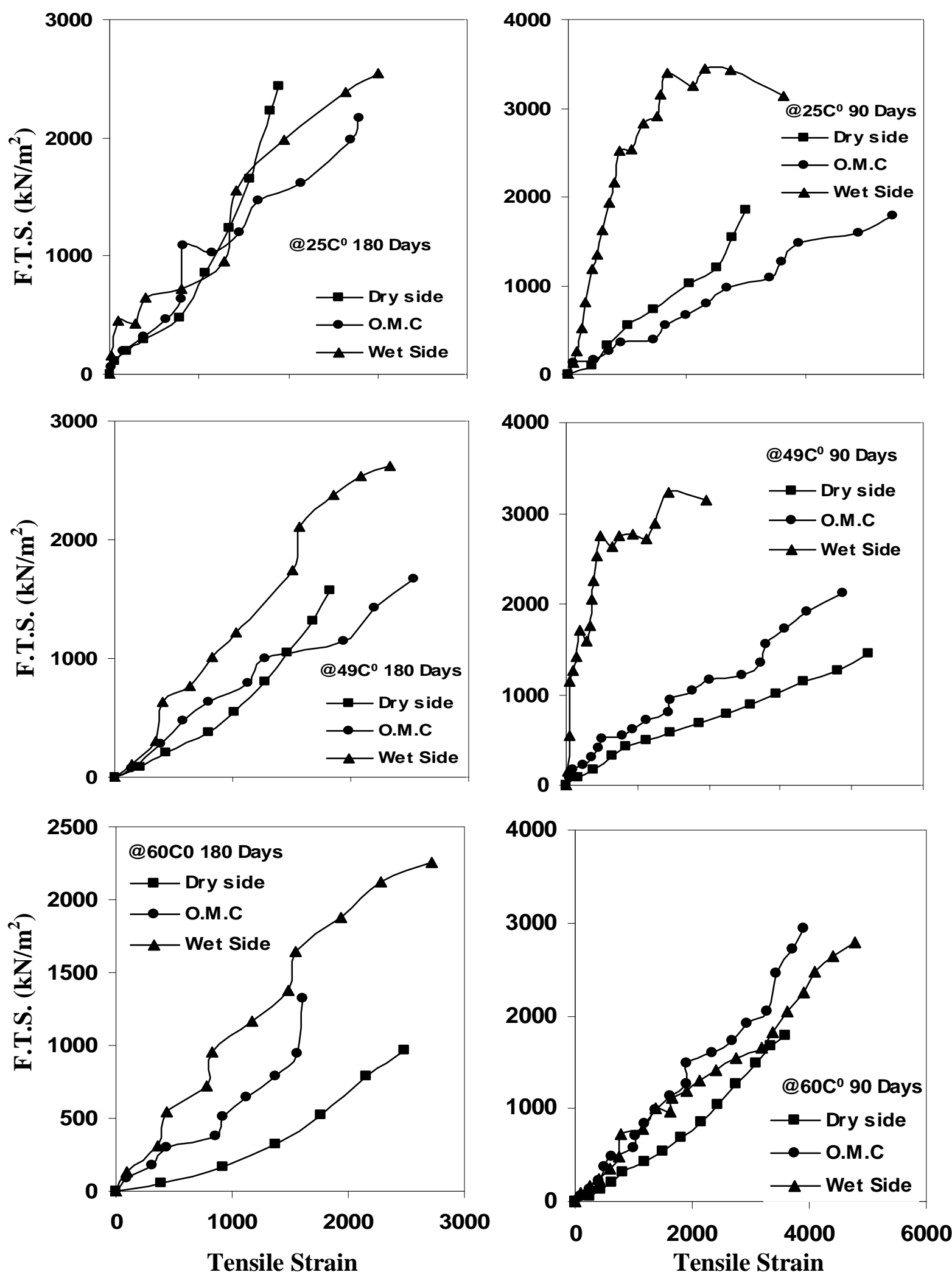

الثكل (7) منحنيات الإجهاد -الانفعال (حب الطريقة المباشرة) 
ألليلة: سلوكية عتبات التربة الجبسية المثبتة بالنورة تحت تأثير الأحمال الساكنة
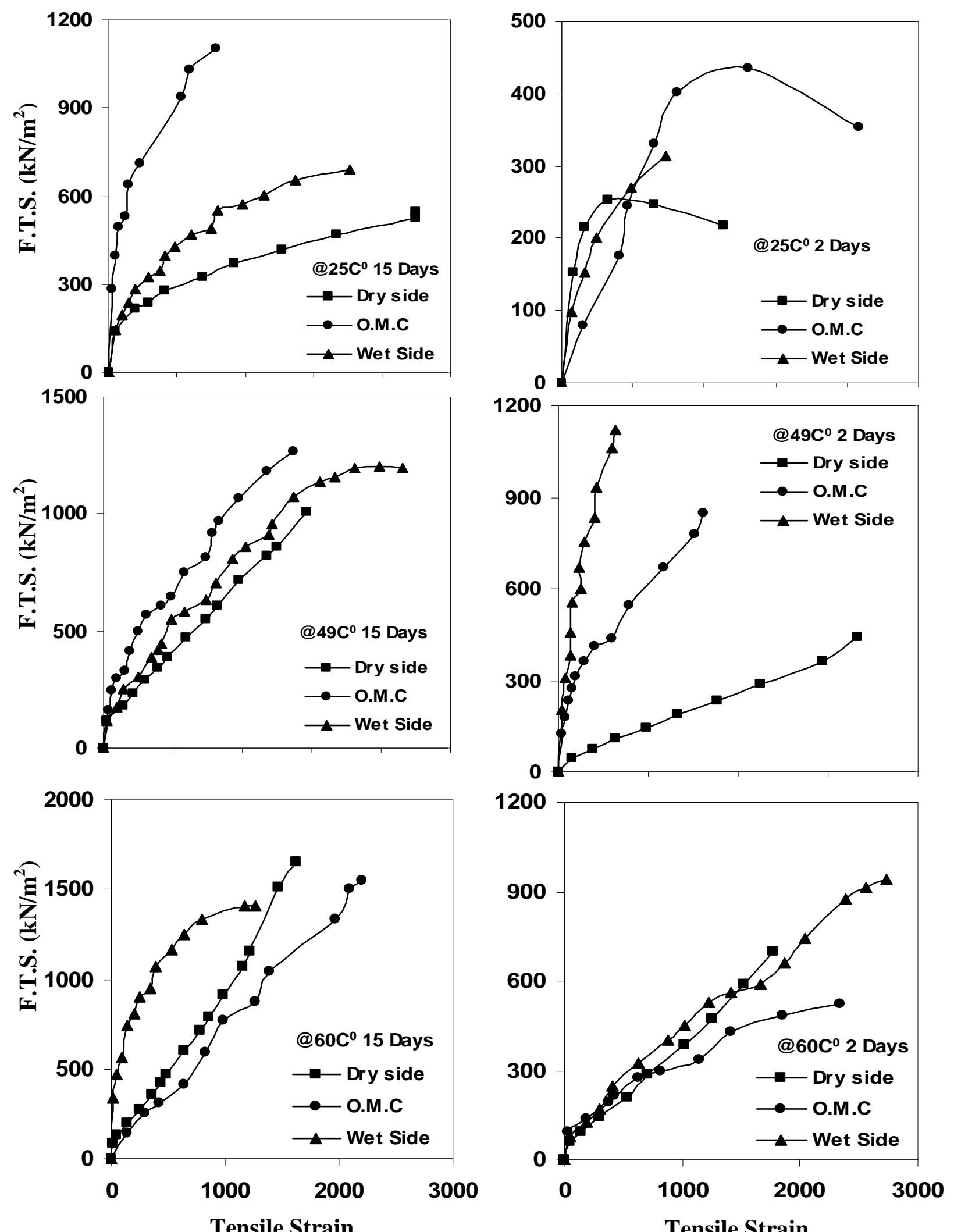

الثكل (8) منحنيات الإجهاد -الانفعال (حسب الطريقة التفاضلية) 

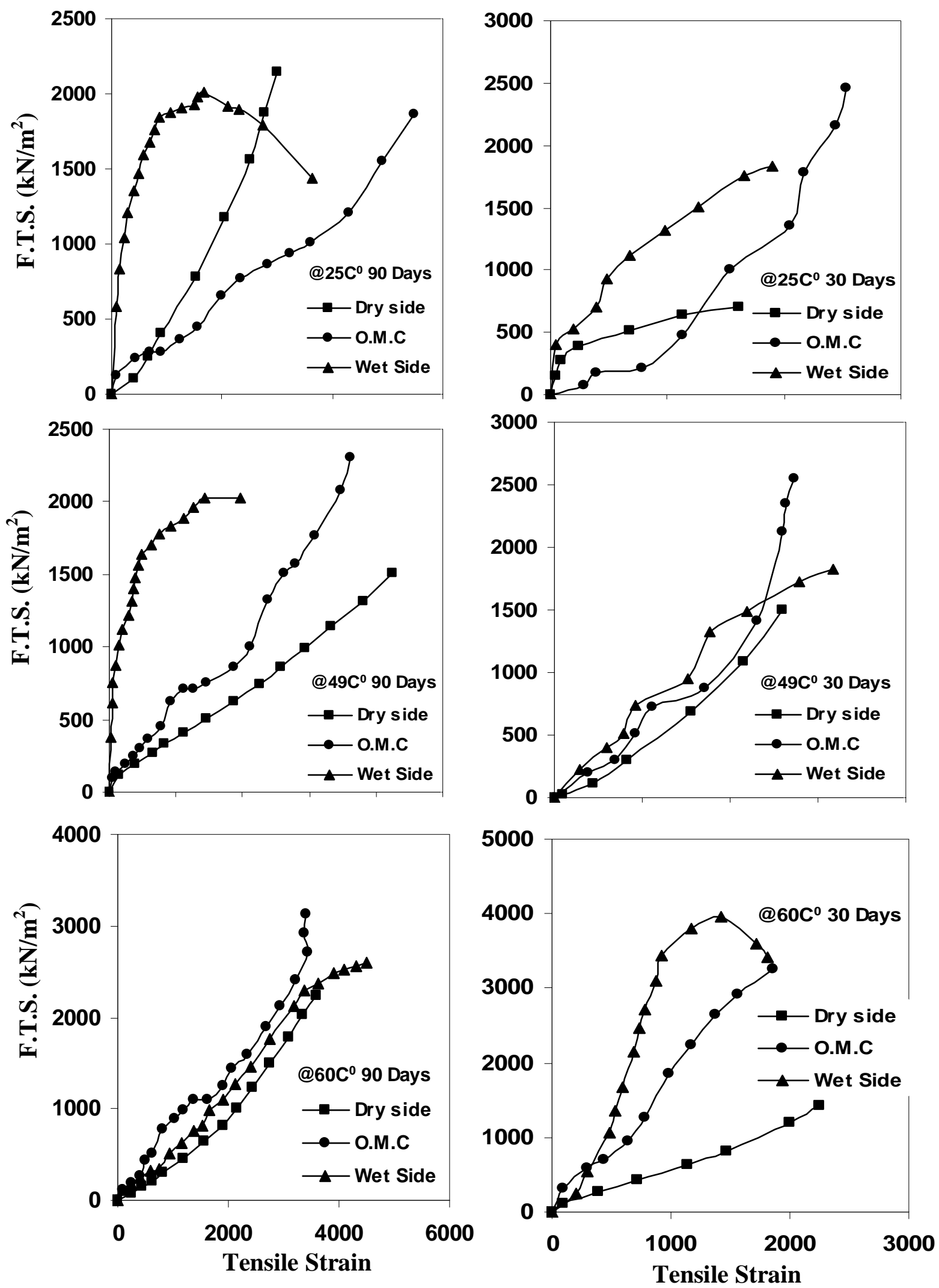

الثكل (9) منحنيات الإجهاد -الاففعال (حسب الطريقة التفاضلية) 

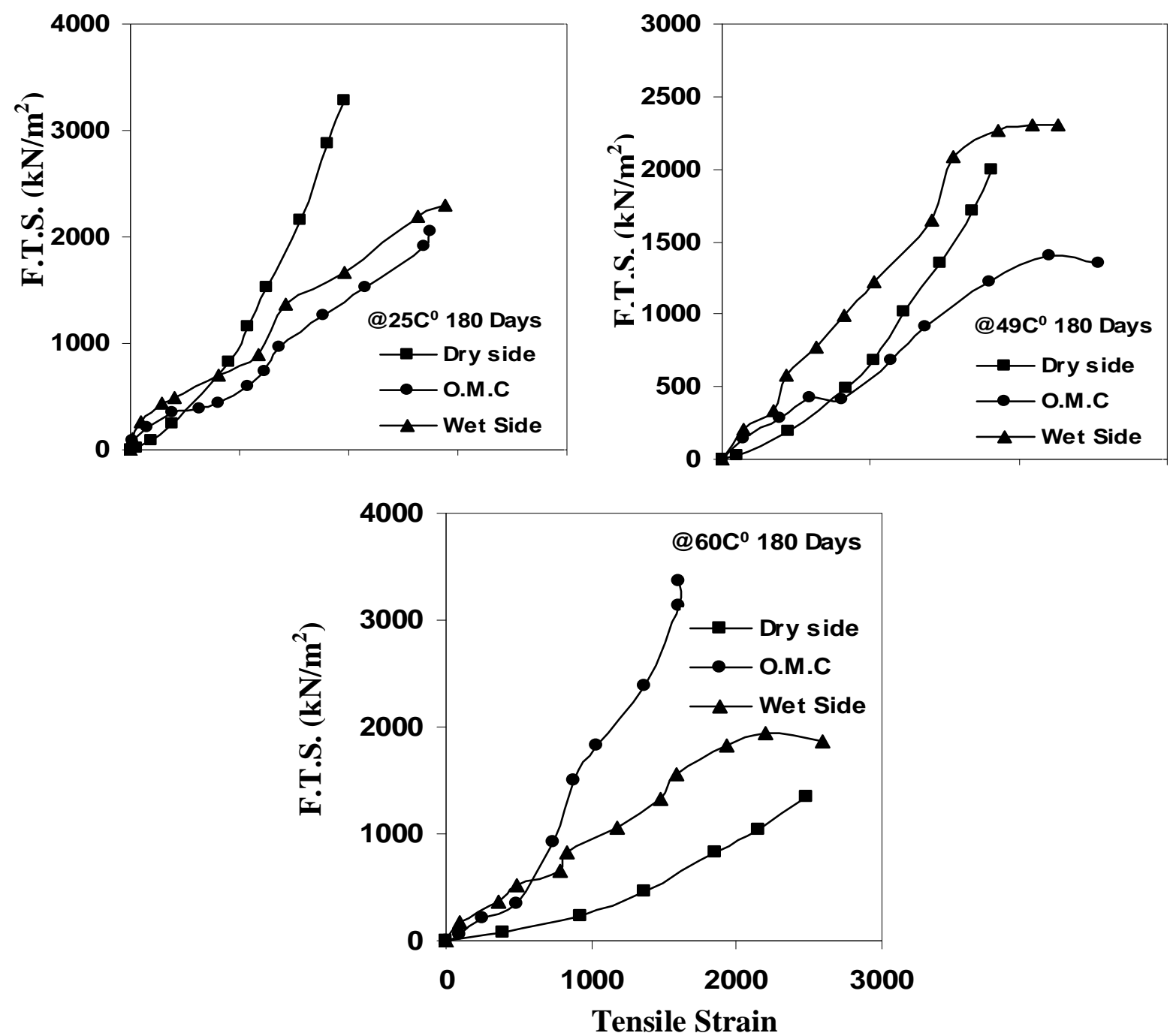

الشكل (10) منحنيات الإجهاد -الاففعال (حسب الطريقة التفاضلية)

الجدول (3) التمثيل الرياضي لمقاومة شد الاثثناء للنماذج المرصوصةعند الجاتب الجاف من منحني الرص

\begin{tabular}{|c|c|c|c|c|}
\hline Elastic Bending Theory Method & $\begin{array}{c}\text { Temp. } \\
\left(C^{0}\right)\end{array}$ & $\begin{array}{l}\text { Type of } \\
\text { Equation }\end{array}$ & Order & $\begin{array}{l}\mathbf{R}^{2} \\
(\%)\end{array}$ \\
\hline$\sigma_{t}=317.37 \operatorname{Ln}(T)-7.9211$ & 25 & Logarithm & ----- & 97.29 \\
\hline$\sigma_{t}=0.0005(T)^{3}-0.1859(T)^{2}+21.979(T)+668.46$ & 49 & Polynomial & $3^{\text {rd }}$ & 99.99 \\
\hline$\sigma_{\mathrm{t}}=0.0016(\mathrm{~T})^{3}-0.540(\mathrm{~T})^{2}+47.326(\mathrm{~T})+732$ & 60 & Polynomial & $3^{\text {rd }}$ & 99.33 \\
\hline \multicolumn{5}{|l|}{ Direct Method } \\
\hline$\sigma_{t}=318.99(T)^{0.3799}$ & 25 & Power & ----- & 98.16 \\
\hline$\sigma_{t}=237.42 \operatorname{Ln}(T)+369.61$ & 49 & Logarithm & ----- & 99.72 \\
\hline$\sigma_{t}=0.0013(T)^{3}-0.4711(T)^{2}+43.169(T)+739.21$ & 60 & Polynomial & $3^{\text {rd }}$ & 81.59 \\
\hline \multicolumn{5}{|l|}{ Differential Method } \\
\hline$\sigma_{t}=118.68(T)^{0.6136}$ & 25 & Power & ----- & 96.18 \\
\hline$\sigma_{t}=328.26 \mathrm{Ln}(\mathrm{T})+208.5$ & 49 & Logarithm & ----- & 94.49 \\
\hline$\sigma_{t}=-0.1424(T)^{2}+28.262(T)+864.91$ & 60 & Polynomial & $2^{\text {nd }}$ & 81.14 \\
\hline
\end{tabular}




$$
\begin{aligned}
& 6 \text { - الاستتناجات } \\
& \text { 1. أن نسبة النورة الني أعطت أعلى مقاومة انضغاط غير محصور هي (3\%) رونفس النسبة أعطت أعلى مقاومسـة } \\
& \text { شد. } \\
& \text { 2. أعطت الطريقة المرنة و الطريقة المباثرة وبصورة عامة قيم مثقاربة لمقاومة شد الانثناء, في حين أعطت الطريقة }
\end{aligned}
$$

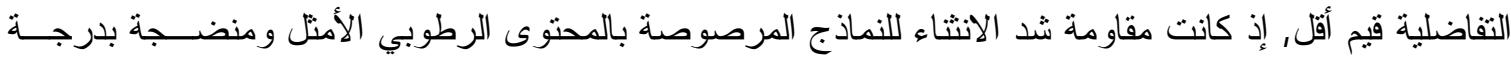

$$
\begin{aligned}
& \text { حر ارة (60 C C لمدة (15) يوم هي (kN/m² 1552, 1672, 1646) حسب الطريقة المرنة, المباشرة و التفاضلية } \\
& \text { على التو الي. كذلك كانت منحنيات الإجهاد -الانفعال المحسوبة بالطريقة المرنة منتظمة, أما المنحنيات المحســـوبة المانة }
\end{aligned}
$$

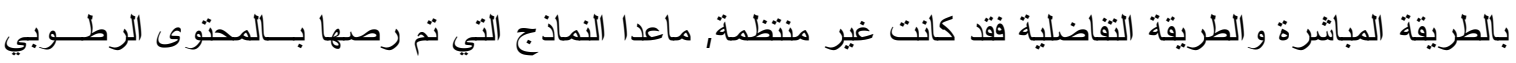

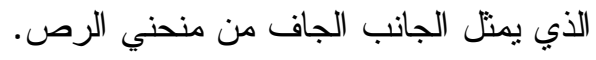

$$
\begin{aligned}
& \text { 3. تعتبر الطريقة المباثرة طريقة مناسبة لإيجاد العلاقة بين الإجهاد -الانفعال و إيجاد قيم مقاومة شـــــ الانثتــاء مــع } \\
& \text { ظروف الإنضاج وقيم الرطوبة المختلفة. }
\end{aligned}
$$

1 Ingles O. G. and Metcalf J. B. "Soil Stabilization Principles and Practice" Sydney, Butterworth, (1972).

2 Sobhan, K. and Mashnad, M. "Fatigue Durability of Stabilized Recycled Aggregate Base Course Containing Fly Ash and Waste-Plastic Strip Reinforcement", Final Report, Recycled Materials Resource Center, University of New Hampshire, (2000).

3 Fossbery, P. E. Mitchell, J. K. and Mouismith, C. L. "Cracking and Edge-Loading Effects on Stresses and Deflections in a Soil Cement Pavement", HRR, No.379, (1972).

4 Ajaz, A. and Parry, R. H. G. "Stress-Strain Behaviour of Two Compacted Clays in Tension and Compression", Journal of Geotechnical Engg., ASCE, Vol.25, No.3, (1975 a), pp.495-512.

5 Consoli, N. C. Prietto, P. D. M. Carraro, J. A. H. and Heineck, K. S. "Behavior of Compacted Soil-Fly Ash Carbide Lime Mixture", Journal of Geotechnical and Geoenviromental Engg., ASCE, Vol.127, No.9, (2001), PP.774-782.

6 Little, D.N. "Handbook for Stabilization of Pavement Sub Grade and Base Courses with Lime", Kendall Hunt Publishing Company, Iowa, USA, by National Lime Association, (1995).

7 Ajaz, A. and Parry, R. H. G. "Analysis of Bending Stresses in soil Beams", Journal of Geotechnical Engg., ASCE, Vol.25, No.3, (1975 b), pp.286-291.

8 Ajaz, A. and Parry, R. H. G. "Bending Tests for Compacted Clays", Journal of Geotechnical Engg., ASCE, Vol.102, No.GT9, (1976), pp.929.

9 Jaro, M. N. "Effect of Fine Material on the Tensile Strength Properties of Unstabilized and Cement-Stabilized Granular Soil", M. Sc. Thesis, Civil Engineering Department, College of Engineering, University of Mosul, (2000).

$$
\text { تم اجراء البحث في كلية الهنسة - جامعة الموصل }
$$

